\title{
河北师范大学国家级化学一流专业建设探索与实践
}

曾艳丽 ${ }^{*}$, 刘博, 韩占刚, 吴秀明, 于海涛, 武明星, 贾密英

河北师范大学化学与材料科学学院, 化学国家级实验教学示范中心(河北师范大学), 石家庄 050024

摘要: 教育是国之大计、党之大计, 教师是立教之本、兴教之源。以河北师范大学化学专业建设为例, 从课程体系 的构建、 “金课” 建设、实践教学和教学管理与评价四个方面, 探讨地方高等师范院校如何立足师范教育开展一流 化学专业建设, 以实现培养 “国家基础教育事业改革发展战略需求的德才兼备的骨干师资”的人才培养目标。

关键词：地方高等师范院校; 一流化学专业; 一流课程; 实践教学

中图分类号: G64; O6

\section{Research and Practice of the Development of the National First-Class Chemistry Major in Hebei Normal University}

Yanli Zeng ", Bo Liu, Zhangang Han, Xiuming Wu, Haitao Yu, Mingxing Wu, Miying Jia

National Experimental Chemistry Teaching Center, College of Chemistry and Material Science, Hebei Normal University, Shijiazhuang 050024, China.

Abstract: Education is the grand plan of the country, and teachers are the foundation and source of education. Taking the construction of chemistry specialty at Hebei Normal University as an example, this paper focused on how to carry out the first-class chemistry major construction from four aspects in the local higher normal university, including the construction of curriculum system, the construction of "golden course", the practice teaching and the teaching management and evaluation, so as to realize the talent training objectives of "national basic education reform and development strategy needs of key teachers with both political integrity and ability".

Key Words: Local higher normal university; First-class chemistry major; First-class course; Practical teaching

教育是国之大计、党之大计, 教师是立教之本、兴教之源。2018年1月20日, 中共中央、国务院 颁布了《关于全面深化新时代教师队伍建设改革的意见》。2018年9月10日, 党中央召开新时代第一 次全国教育大会, 习近平总书记要求坚持把教师队伍建设作为基础工作。河北师范大学作为地方师 范大学, 以党的十九大精神为指引, 高举习近平新时代中国特色社会主义思想伟大旗帜, 不忘初心, 牢记使命, 教书育人, 立德树人, 积极推动内涵式发展, 以建成 “具有鲜明教师教育特色的高水平 综合性大学”为发展目标。

化学专业知识、学科教学知识、教育反思能力和研究能力是卓越教师职前培养的重要内容 ${ }^{[1]}$ 。 河北师范大学化学一流专业建设结合学校教学改革的整体布局, 充分发挥化学优势专业作用, 坚持 以学生为中心, 秉承知识、能力、素质全面协调发展的教学理念, 把立德树人具体化, 深化教育教

收稿: 2020-11-30; 录用: 2020-12-25; 网络发表: 2021-01-04

“通讯作者, Email: yanlizeng@hebtu.edu.cn

基金资助: 国家级一流本科专业建设点项目(2019 年度); 国家级一流本科课程 “结构化学” 建设项目(2020 年度); 河北省高等教育教学改革研 究与实践项目(2019GJJG114) 
学改革, 全面提升人才培养质量; 结合专业定位, 以师范专业认证建设标准为指导, 全面服务于人 才培养; 以培养有理想信念、有道德情操、有扎实学识、有仁爱之心 “四有” 好教师为目标, 兼顾 部分学生继续深造的要求, 既注重师范生职业道德素养、文化科学素养、业务能力素养和教育心理 素养的全面养成, 又注重学生扎实化学基础知识与实验技能的习得。本文以河北师范大学化学专业 建设为例, 从课程体系的构建、 “金课” 建设、实践教学和教学管理与评价四个方面, 探讨地方高等 师范院校如何立足师范教育开展一流化学专业建设, 以实现上述人才培养目标。

\section{1 基于成果导向教育(OBE)理念, 构建符合新时代人才培养目标的专业课程体系}

河北师范大学化学专业人才培养目标是培养具有社会主义核心价值观, 立足河北, 服务京津冀, 面向全国, 适应新时代中学化学教育发展需求, 具有系统扎实的化学专业以及物理、生物、数学、 计算机、外语等相关学科的理论知识和实践技能, 具备自主学习和自我发展能力、创新意识以及先 进的教育理念，适应国家基础教育事业改革发展战略需求的德才兼备的骨干师资。

基于上述人才培养目标, 我们依据教育部高等学校化学类专业教学指导委员会制订的《化学类 专业教学质量国家标准》 ${ }^{[2]}$ 、《化学类专业化学理论教学建议内容》和《化学类专业化学实验教学建 议内容》, 参考基于学科思维的化学类专业课程体系设计 ${ }^{[3]}$, 修订了化学专业课程教学内容和教学 要求。我们根据 “加强基础、拓宽口径、尊重个性、重在创新” 的发展思路, 秉承 “学生中心、产 出导向、持续改进” 的OBE理念, 切实加强和抓实人才培养质量。自2014级本科生开始, 实施分类 分层次教学, 设置 “创新实验班” 和 “从教技能提高班” , 并构建了兼顾师范类高校定位和办学特 色, 符合化学专业培养目标和毕业要求, 尊重学生个性发展, 支撑人才培养目标的分层次专业课程 体系。该课程体系遵循因材施教原则, 采取全新的教育理念、培养体系和管理模式, 满足了学生发 展的个性化需求, 提升了学生培养质量。

我们的化学专业课程从培养学生的道德品质、化学专业素养、教育情怀、实践能力和综合素质 五个层面, 分别构建了通识类、专业平台类、教师教育类、实践教学类和综合素质类五大 “第一课 堂”课程模块, 各个模块紧密联系、高度融合, 力求实现全方位、立体育人的目标。

通识类课程模块注重塑造学生对社会的认知, 帮助学生树立良好的世界观、价值观和人生观, 培养德、智、体、美、劳全面发展的 “四有” 好教师。本模块必修课程不仅包含形势与政策、思想 道德修养与法律基础、马克思主义基本原理概论、毛泽东思想和中国特色社会主义理论体系概论、 习近平新时代中国特色社会主义思想概论等思想政治理论课, 也包含大学体育、大学英语、信息技 术基础、计算机程序设计基础等提升学生能力的综合素质课程。本模块选修课程则根据课程门类又 细分为文史经典与文化传承、哲学智慧与艺术感悟、科学技术与创新实践、社会发展与社会治理、 自我管理与持续发展等五个系列, 让学生可以根据自己的兴趣和自身需要进行个性化发展。

专业平台类课程则聚焦于培养学生化学学科素养和科研素质。本模块不仅包含无机化学、有机 化学、物理化学、分析化学、结构化学等必修课程, 以扎实培养学生的化学专业基础知识, 也包含 纳米材料、有机功能材料、胶体化学、化学电源、环境化学等学科前沿发展内容的选修课程, 满足 学生个性化发展的需要, 拓展学生多方位专业视野, 培养学生对化学科研的兴趣, 提升学生对专业 的认同感。

教师教育类课程在传授和锻炼学生教学技能的同时, 更注重学生教育情怀的培育, 帮助学生成 为一名有灵魂、有信念、有思想、有情怀、有学识、有担当、有使命感、有仁爱之心的未来教师。 因此, 本模块不仅包含教育学基础、心理学基础、中学化学教学理论与教学设计、教师语言文字技 能训练等教育学基础理论的课程, 还包括教育哲学、中学学科教学专题案例分析、新教师入职适应 实训等更贴近教学实际的课程。

实践教学类课程主要突出实践能力、探索和创新精神的培养, 服务于国家创新驱动发展战略。 根据实践内容分为化学专业实验部分和教学技能实践部分：化学专业实验课程不仅包括无机化学实 
验、有机化学实验、物理化学实验、分析化学实验等基础实验课程, 还包括综合化学实验和研究设 计实验等来源于教师科研成果转化的综合性实验, 全方位、多方面锻炼和提升学生实验技能, 培养 学生科研探索精神; 而教学技能实践部分则是设置了顶岗实习和教育实习两种方式, 让师范类学生 有一学期的时间全身心投入到中学教学一线进行实践, 他们或作为顶岗教师负责一个班级全面的日 常教学工作, 或作为助教和班主任与中学教师共同进行教学工作。通过一个学期的教学实践, 学生 的教学技能普遍能够得到大幅度提升, 丰富专业知识和拓展专业视野的同时, 真正实现了 “学” 和 “教” 的结合, 以此更有利于他们今后的职业规划和发展。

综合素质类课程则设置了包括大学生心理健康教育、军事理论、军事训练、大学生生涯发展与 就业指导、普通话、大学生创业教育等能够全面提升学生各方面素质的课程。

此外, 我们还组建了丰富多彩的 “第二课堂” , 实现全面育人。通过专家讲座、教学见习、模 拟授课、教学比赛、大学生科技创新等活动, 为学生提供了解教育实际、关注学科动态、参与科学 研究、培养科学素养的 “学分生长” 土壤, 努力实现巩固专业思想、提高专业能力、开阔专业视野、 实现专业发展的过程育人。分层次的 “第一课堂” 和开阔视野 “第二课堂” 相辅相成, 真正组成了 一套以学生为中心, 紧跟社会发展需求, 符合新时代OBE理念人才培养目标的课程体系。同时, 这 套课程体系仍然需要根据社会和学科的发展不断改进和优化, 与时俱进地做好课程设计和课程内容 的更新、取舍和协调。

\section{2 以教学团队为抓手, 分层次打造化学专业 “金课” 群}

在2018年6月21日召开的 “新时代全国高等学校本科教育工作会” 上, 教育部陈宝生部长第一次 提出了 “金课” 概念, 随后 8 月份教育部印发了《关于狠抓新时代全国高等学校本科教育工作会议精 神落实的通知》 (教高函 [2018]8号), 提出 “各高校要全面梳理各门课程的教学内容, 淘汰 “水课” 打造 “金课”, 切实提高课程教学质量”。

一流本科教育, 专业是基本主体, 课程是核心环节。一流专业建设不仅要有科学合理的课程体 系, 更要有能够实现课程体系设置初衷的课程内容和教学团队。2018年11月24日, 在第十一届 “中 国大学教学论坛” 上, 教育部高等教育司司长吴岩作了题为 “建设中国金课” 的报告, 提出了建设 五大 “金课” 的目标, 包括线下 “金课”、线上 “金课”、线上线下混合式 “金课”、虚拟仿真 “金课” 和社会实践 “金课”。打造金课，必须要充分重视课堂教学这一主阵地，努力营造课堂教学热烈氛围; 要合理运用现代信息技术手段, 积极推进慕课建设与应用, 开展基于慕课的线上线下混合式教学。 基于上述思路, 我们以教学团队为抓手, 进一步强化 “以学生为中心” 的教育教学理念, 持续推进 以课堂教学改革为突破口的人才培养模式的教育教学改革, 分层次推动化学 “金课”建设。

我们首先将线下 “金课” 作为课程建设的第一层次，也是其余几类 “金课” 建设的基础。我们 以夯实学生基础知识和培养学生从教能力为出发点, 在课程设计方面以学生为中心, 从人才培养角 度提出学生通过学习后可取得的学习成果目标, 包括知识、能力、素质等几个方面, 围绕学习成果 目标, 安排每一章节的教学活动, 明确提出学习要求, 制定评价方式和考核标准; 课程内容方面, 将化学基础知识与课程思政元素有机结合, 在传授知识的同时对学生进行潜移默化的思政教育; 授 课模式则是将传统授课模式与以学生为中心的教学模式相结合, 既注重知识结构的形成, 又注重学 生创新能力、探索能力、自主学习能力、教材分析能力、课堂组织能力的培养; 最后的评价体系我 们也抛弃了传统的 “一考定胜负” 的考核模式, 采用更强调学习过程的过程化考核体系, 希望能够 通过对学习过程的考核, 激励和督促学生更高效的学习, 提高学习效果。通过上述从 “教” 到 “学” 到 “评” 的全方位改革, 学院凭借 “卓越化学教师 “立体化培养” 课程结构体系的构建与实践” 和 “基于提升大学生科研素养的创新型化学人才培养模式构建” 两个河北省高等教育教学改革与实践 项目, 分别在2017年和2019年获得第七届河北省高等教育教学成果二等奖和第八届河北省高等教育 教学成果一等奖。经过几年的建设, 各教学团队也都已经逐渐培育出自己的特色精品课, 例如结构 
化学教学团队曾艳丽教授主讲的结构化学于 2020 年获批国家级和河北省一流线下本科课程建设立 项, 另有无机化学、物理化学和分析化学等课程获得学校一流本科课程建设立项。

在上述线下 “金课” 建设的基础上, 我们逐步组织各教学团队将各门主干课的经典知识和经典 理论分批分期录制为线上课程, 积极打造第二层次的线上线下混合 “金课” 和建设具有完整线上教 学内容的第三层次的线上 “金课”。由于 2020 年的疫情原因, 线下教学全面转到线上, 老师和学生都 迅速熟悉并掌握了线上教学平台的使用。以此为契机, 我们把这些录制好的课程放在超星学习通等 线上教学平台, 并设置了相应的学习任务、作业以及小测, 将线下课程逐步过渡为线上线下混合课 程。教师提前布置任务, 作为课程过程化考核的一部分, 让学生先进行线上学习, 并完成相应的学 习任务, 然后再进入课堂完成线下学习, 目前来看也已经取得了不错的教学效果。通过不断获取学 生反馈信息, 持续改进和完善线上和线下教学内容和教学方式, 使二者相互融合、相互促进, 真正 实现线上线下教学互补, 力争打造第二层次的线上线下混合 “金课”。在不断丰富和完善线上课程内 容的基础上，最终打造具有完整线上教学内容的第三层次的线上 “金课”。

无论是第二层次的线上线下混合 “金课” 还是第三层次的线上 “金课”, 都是以第一层次的线下 “金课” 为基础, 没有线下课程作为基础, 线上课程只能是空中楼阁。因此, 不同层次的 “金课” 建设仍然要以线下 “金课” 作为主战场, 苦练内功, 打牢基础, 才能让课程建设不断前进, 枝繁叶 茂。

\section{3 立足师范特色, 进行分层次的实验和实践教学}

积极响应国家创新驱动发展战略。化学师范专业建设过程中, 我们始终坚持创新实践能力培养, 集聚优质教育资源, 构建 “UGS” (大学、政府、中小学)协同育人机制, 形成了 “全过程贯通、课内 外贯通、校内外贯通” 的 “三贯通” 实践教学模式。始终强调实践教学要与学科建设、教学改革及 科学研究紧密结合, 相互之间形成联动关系, 不断增强实践教学在培养高素质创新人才中的重要地 位和作用。

\section{1 夯实基础实验技能, 培养科研探索精神}

能力培养作为贯穿学生大学学习阶段的主线, 理论教学与实践教学是保证主线前行的两翼, 实 践教学与理论教学是侧重点各有不同的有机统一整体。实践教学体系在内容设计上保证实验教学与 理论教学相互支撑、基础知识基本技能训练与综合设计性实验的合理设置。依据课程内容的递进关 系, 实验教学分为基础实验、综合实验和研究设计实验三个层次逐渐展开: 基础实验方面, 打破原 来局限于无机化学实验、有机化学实验、分析化学实验、物理化学实验的格局, 重新设计优化衔接 关系, 四个模块共同构成专业基础实验; 综合实验属于较高层次的实验课程, 在基础实验的基本实 验知识和技能掌握的基础上, 整合各个学科的实验内容并融入部分教师的前沿科研成果, 综合性 设置实验内容, 让学生系统性掌握化学学科的实验思想和操作, 注重培养学生科学实验的整体观和 全局观; 研究设计实验同样是由教师的科研成果内化而来, 但更侧重于探究设计意识的培养, 促进 学生的科研探索精神的形成, 提高其实践创新能力。具体的实验课程安排如下: 无机化学实验 (108 学时)、普通物理实验(36学时)、有机化学实验(90学时)、分析化学实验(54学时)、仪器分析实验(36学 时)、物理化学实验(72学时)、化工基础实验(36学时)、综合化学实验(72学时)、研究设计实验(36学 时)、毕业论文(1学期, 6学分)。实验教学按照 36 学时 1 学分设置, 这些实践教学环节共 21 学分, 占总 学分 155 的 $13.5 \%$; 综合化学实验和研究设计实验的学分/课时占所有实验学分/课时的 $20 \%$ 。

学院依托计算量子化学科研团队的教学和科研成果 ${ }^{[4-7]}$, 提炼了可以针对本科生开设的研究探索 性实验, 开设了计算化学实验课程。学生通过计算化学实验模拟化学反应过程、药物笁选和药物分 子设计过程, 从而加强理解抽象的理论原理与实际生活之间的联系。在此过程中, 理论联系实际, 更好地培养了学生的科研计算理论思想, 提升了他们的科研兴趣。

实验课程的考试, 根据学生的预习报告、课堂提问、操作技能、实验报告质量以及考勤情况, 
综合评定学生实验课成绩。通过实验技能抽查等对实验教学效果和质量进行全程监控, 了解学生对 基本原理和实验的掌握情况。对每门实验课程, 在总结多年实验考核方法基础上构建了多元化的实 验成绩考核管理办法。以有机化学实验考核为例, 平时实验占 $40 \%$, 期末操作考试实验占 $30 \%$ (其中 根据具体实验指定各操作环节评分细则占 $70 \%$, 学生实验考核结束后以书面形式提交实验报告占 $30 \%)$, 理论考试占 $30 \%$ 。建立了平时考核登记表, 从实验预习、实验操作、实验记录、实验态度、 实验互动、实验纪律、实验报告等方面设立考核点及分值, 综合确定平时成绩; 期末实验考试由任 课教师讨论选择重要的基本技能操作或一个具有代表性的实验作为考试的实验。

基于前期的实验教学改革, 我们组织编写了《化学实验》(上、中、下册)教材, 包含基础实验模 块、综合化学实验模块、创新设计实验模块、计算化学实验模块, 2016年由化学工业出版社出版。 该教材具有以下特点: (1) 层次化与整体性统一。化学实验作为一门独立课程设置, 其实验内容与教 学进度独立于理论课, 通过实验内容的分层次设计, 构建一个系统、完整的实验教学新体系。(2) 经 典性与现代性统一。教材精选了以往教学中的一些经典实验内容, 选择了一些成熟的、有代表性的 现代教学科研成果, 一方面加强学生实验技术与技能的训练, 另一方面强化学生研究和创造能力的 培养。(3) 知识性与实用性的统一。教材既涉及化学实验基础知识和操作训练, 又涉及无机物制备、 有机物合成、工业品质量检测、环境分析、天然产物提取等应用性内容。(4) 专业性与师范性的统 一。体现师范院校的教师教育及化学学科专业性的特点, 在注重化学学科的专业知识、专业技能训 练的同时, 强化专业知识和技能与其他相关学科知识与技能的联系, 强化从专业学习到专业施教的 过渡。

此外, 我们还以课堂学习为基础, 学生与专业教师之间紧密联系, 构建了致力于学生基础理论、 科研基本素质培养的教学、科研、学生工作三位一体的培养体系。同时, 我们开设了以优秀青年教 师为主、优秀研究生和本科生为辅的 “面向化学类本科生科研基本素质培养” 系列讲座, 强化学生 科研基本能力的培养。近年来, 每年参加到教师科研团队中的学生人数呈逐年递增的趋势。目前学 生参与科研活动人数达到70\%。2015-2019年期间, 我院本科生共承担国家级大学生实践创新训练计 划项目 30 项; 省级大学生实践创新训练计划项目 52项, 校级大学生实践创新训练计划项目 106项。参 加大学生实践创新训练计划项目的本科生共发表 SCI学术论文 100 余篇, 并有科研成果申报了发明专 利。推进了科研反哺教学, 提高了学生的创新意识和创新能力。

\section{2 以顶岗实习为抓手, 切实提升教学技能}

河北师范大学是国内较早探索 “三位一体” 协同培养机制的师范院校。学校自2006年正式启动 “顶岗实习支教工程” 以来, 持续开展师范生在教学一线为期半年的实习支教的培养模式。通过搭 建UGS协同发展平台, 学校曾参与多个教育部有关师范生实习支教文件的调研、论证与制订。该机 制通过整合优质教育资源, 实行高校教师与地方名师对实习生联合指导制度, 有计划组织实践基地 学校教师培训参加 “国培” 与 “省培”, 建立中学教改课程实验基地, 成立 “京津冀基础教育合作共 同体” 等, 服务河北省与京津地区基础教育发展。使职前职后一体化培养模式取得了实践教学和社 会服务的良好效果。

基于此, 我们在化学专业本科生中积极推动建立 “讲授-读书-研讨-实训-调查” 五位一体的人 才培养机制和模式。在第 5 学期开展顶岗实习前的教学技能实训互动, 以教师职业技能训练中心为平 台, 聘请省内中学教学一线高级教师担任指导导师。将实训活动与学生课程相联系, 结合 “中学化 学教学技能训练” 及 “中学化学见习、研习” 两门实践课程, 把中学一线化学教师请进化学专业教 学课堂, 结合案例为本科生讲解教学技能; 把本科生带进中学课堂, 实地观摩教学, 熟悉中学教育, 增强教师的责任感; 在实训室中完成教学视频录制, 中学教师实时点评, 手把手传授教学心得, 促 进本科生由 “学生” 向 “教师” 身份逐步过渡。积极利用学校信息化资源, 运用远程网络直播的方 式参与中学见习研习, 强化实践教学的情境性、现场性; 用好 “中学教育见习研习” 慕课平台, 一 方面形成交互式、研讨式的学习方式, 另一方面搜集整理学生在见习研习等实践教学环节中存在的 
问题, 形成实践教学问题资源库。顶岗实习初期, 实习县市教育局、进修学校或实习学校对实习生 组织3-5天的岗前培训。内容包括: 县情校情学情、师德、教学技能提升等方面内容。培训后, 实习 生开始在实习指导教师、特聘名师、驻县管理教师的教学指导下进入听课、备课、试讲等教学环节。 实习期间, 强调教学指导的重要作用, 要求实习生接受实习指导教师、特聘名师、巡回指导教师、 远程教学全方位指导。除了实习期间网络形式的专业课程, 还在实习前和实习中为师范生开设了 “中 学教育见习与实习” 慕课课程。本课程以SPOC和MOOC形式, 在爱课程(中国大学MOOC)和学堂在 线两平台, 面向社会学习者和全校师范生开设。

此外, 从2006年实施 “顶岗实习支教工程” 开始, 我们就逐渐建立和完善了师范生教育实践的 “双导师” 指导制度, 对导师遴选、工作要求、业务培训、实践指导、条件保障等提出明确要求。 采取驻校指导、巡回指导和远程指导等多种方式, 通过专题研究、协同教研、定期培训等多种形式, 不断提高 “双导师” 的专业化水平和实践指导能力。通过 “校内挖潜”, 在校内由全部的教师教育课 程任课教师(化学教学论教师)、优秀的化学专业教师组成理论导师(巡回指导、远程指导)指导队伍。 在实习中期开展面对面巡回教学指导, 远程指导则从实习开始贯彻始终。要求每位教学论教师每学 期都要进行UGS合作教研, 要求每学期进行指导交流的时间不少于 15 天(含教学巡回指导、远程指导、 作业评价); 通过 “名师领衔”, 当地实习学校为每一位实习生配备一对一学科指导教师并要求实习 生主动拜师, 要求实习县市教育主管部门组织特聘名师队伍定期指导实习生, 一般 5 名实习生配备一 名特聘名师。

在每期理论导师巡回指导出发前, 都多次召开专家研讨会和理论导师培训会, 就如何开展听课 评课以及相关注意事项进行培训。我们还定期召开教学论教师教研活动, 制定了教师教育教研工作 管理制度, 开展校内同伴交流、学科教学改革教学观摩与展示活动。积极发挥高水平教师的引领作 用, 提高指导教师专业素养和能力。

通过上述贯穿顶岗实习各个环节的培训和指导, 化学专业各届学生顶岗实习人数占比 $80 \%$, 优 秀率历届均在 $70 \%$ 以上, 在学校各专业对比中名列前茅。近年来, 以我院刘博文、罗颖为代表的优 秀学生的教学能力得到了社会的充分肯定和关注, 中国教育新闻网2018年1月3日报道我校顶岗实习 工作时被重点提到 ${ }^{[8]}$ 。顶岗实习学生积极的表现, 锻炼了学生良好的从教技能, 凡经过顶岗实习实 践的学生, 教师资格证考试的面试通过率能够达到 $98 \%$ 以上。

\section{4 对应一流本科专业建设要素, 分层次打造科学合理的本科生培养质量保障和评价体系}

对应一流化学本科专业建设的各个要素, 基于OBE理念, 我们以 “五度” (专业培养目标与培养 效果的达成度、专业定位与社会需求的适应度、教师及教学资源的支撑度、质量保障体系运行的有 效度、学生和用人单位的满意度)为主线, 形成从学生入口到出口、培养目标到课程体系、课堂教学 到考核评价、资源投入到政策机制的分层次质量保障体系, 实现校内校外 “双层闭环” “评价-反馈改进” 自查自纠的质量保障机制, 将质量要求内化为全校师生的共同价值追求和自觉行为, 落实本 科教学中心地位, 培育持续改进的质量文化。

\section{1 学校和学院层面}

以学校和学院两级教学指导委员会为中心形成了本科教学工作的指导和监督机制。两级教学指 导委员会注重为专业教师提供教学工作相关政策咨询服务与教学规范的监督, 全面做好教学的组织 保障和质量保障, 完善督导与评价机制, 推进教学科研等有效评价; 规范教学管理, 对全过程实施 质量监控。

\section{2 化学专业层面}

以师范专业认证三级标准为目标, 改革学生学业成绩评价体系、教师教学业绩考核方式、实践 教学等关键点, 以教研室为主体负责调研和修订本专业人才培养方案、组织教师听评课、毕业论文 环节以及科研创新训练方面的指导工作, 从而有效助推教师教学方式转变、学生课堂主体地位落实 
和学习成效提升。2020年7月21日, 教育部办公厅发布《教育部办公厅关于公布2020年通过普通高等 学校师范类专业认证的专业名单的通知》, 我校化学专业在列, 顺利通过 2019 年教育部师范类专业二 级认证, 认证结论有效期六年, 自2020年7月起至2026年6月止。

\section{3 教师个体层面}

要求任课教师开展定期和不定期相结合的教研活动, 所有教师每学期至少要听取本学院和其他 学院8次课, 并填写《河北师范大学听课表(理论/实验)》上交学院。学院领导每月至少听本院本科课 程5次, 填写《河北师范大学听课表(理论/实验)》上交到学校教务处。同时以院系领导听评课、师生 座谈会、教学档案建设等为依托形成了对教师个体教育过程各环节的监控机制。院系领导通过听评 课, 及时发现教师教学过程中存在的问题, 并在与相关任课教师交流反馈的基础之上, 对于普遍性 的问题在基层教研室组织及学院大会上进行集体反馈, 提出改进教学工作的意见和建议。通过召开 不同形式、不同层面的师生座谈会, 了解和收集与本科教学各个环节密切相关的信息, 以此来拓宽 教学信息反馈的渠道, 增强对于课堂教育教学工作指导的切实性和有效性。

\section{4 学生层面}

为保证学生毕业时能够达到本专业的相关毕业要求, 学生毕业后具有良好的社会适应能力与就 业竞争力, 针对不同年级专业学习特点, 采取突出重点、分段规划、全过程监控的方式, 对学生在 整个学习过程中的表现进行跟踪与评估, 通过过程式评价, 记录学生学习效果, 通过学风建设措施, 实现培优扶弱, 促进学生专业能力的达成。根据《化学与材料科学学院本科生学业预警管理办法(修 订)》的相关要求, 每学期对于加权平均分低于75分和有不及格科目的学生, 辅导员一对一约谈, 下 发《学业预警通知单》, 建立蓝色、黄色、橙色和红色四级预警档案, 帮助分析学习成绩落后的原因 及改进措施。各年级各班召开学风分析报告会, 对学期末班级的学习成绩进行系统的分析, 总结学 风建设效果、通报学风督察情况、提出提升方案, 通过各科优秀率、通过率的比较, 帮助学生对标 定位。对加权平均分低于75分的同学进行一对一约谈, 建立七五训练营: 加权平均分低于75分的学 生结对帮扶, 集中自习, 集体作业, 中期测验, 定期邀请优秀学生交流研讨座谈经验, 直至成绩达 标。

为加强学风建设, 创设良好育人氛围, 学院实施了学风建设和督查机制。通过抓 “龙头”学生干部先教育机制、抓 “抬头”一—脱机课堂手机收纳机制、抓 “带头” ——榜样力量引领机制、抓 “后头”一一学业预警机制、抓 “心头”一一班级宿舍公约机制, 实现学风建设共建共享。在学校学 风督察、教学督导的基础上, 学院成立纪律督察部, 加强课堂考勤、晚自习检查、宿舍纪律抽查等 基础文明行为督察工作。针对新疆籍少数民族学生, 从入学开始实施 “宝贝陪读计划”, “ $1+1+1$ ” 帮扶互助小组— 1 名新疆籍学生 +1 名学生骨干 +1 名宿舍同学, 帮助他们顺利完成学业, 实现思想认 识、普通话水平和职业技能的同步提升。

在建立上述培养质量保障体系的同时, 学院还建有对毕业生持续跟踪反馈的机制。通过每年1011月份毕业生质量跟踪调查, 学院到用人单位进行走访座谈、发放问卷等途径, 了解毕业生培养质 量和发展情况。根据近三年的毕业生调查结果, 本专业毕业生对各项毕业要求均具有较高的认可度 (超过 $95 \%$ )。学院每年按照本专业毕业要求设计专门表格, 向用人单位邮寄满意度调查问卷。学院领 导也通过走访用人单位, 进行满意度调查。整体而言, 受访的用人单位对师范生的毕业要求具有较 高的认可度。学院定期对校内外的评价结果进行综合分析, 根据《河北师范大学关于修订本科课程 计划的指导性意见》, 定期修订本专业的培养目标和课程计划, 以保证培养目标更好地达成, 推动师 范生培养质量持续改进和提高。

通过建立立体化的培养质量保障和评价体系, 不仅保障了本专业教学较好的教学效果, 还用制 度和评价激励教师不断提高教育教学水平。2019年我院曾艳丽教授主讲的结构化学课程获河北师范 大学首届 “金课大比武” 获奖课程, 2020年我院教师张怀玉在河北省高校青年教师教学竟赛中荣获 理科组一等奖。 


\section{5 结语}

经过多年的深耕建设, 河北师范大学化学专业形成了系统传授和探索研究相结合, 以培养学生 实践教学能力和创新能力为核心的化学专业建设体系; 形成了以学科-博士点-一流专业-一流课程实验教学示范中心建设为框架的学科-专业-课程建设格局。化学专业已经逐渐成为办学条件先进、 师资力量雄厚、人才培养模式科学, 并使教学内容与课程体系、教学方法与手段、教学管理、人才 培养质量等方面在省内领先、国内一流的具有显著师范特色的化学本科专业。

参 考 文 献

[1] 万坚, 邓阳, 原弘, 余能芳, 龚静鸣, 李永健, 温丽丽, 张文华, 郭能, 李武客, 等. 大学化学, 2021, 36 (5), 2007040.

[2] 张树永, 朱亚先. 中国大学教学, 2018, No. 7, 55.

[3] 张树永, 朱亚先. 大学化学, 2017, 32 (1), 9.

[4] 曾艳丽, 李晓艳, 孟令鹏, 郑世钧. 大学化学, 2005, 20 (3), 56 .

[5] 曾艳丽, 李晓艳, 孟令鹏, 郑世钧. 大学化学, 2008, 23 (1), 58 .

[6] 李晓艳, 曾艳丽, 孟令鹏, 郑世钧. 大学化学, 2010, 25 (4), 81.

[7] 李晓艳, 曾艳丽, 孙政, 孟令鹏, 郑世钧. 大学化学, 2016, 31 (1), 79 .

[8]中国教育新闻网. [2021-01-01]. http://www.jyb.cn/zgjyb/201801/t20180103_916731.html 